\title{
Research on the Correlation Between Energy Reform and City Development Based on Cointegration and Causality Analysis - Part 1 The correlation analysis
}

\author{
Yan ZHANG ${ }^{1}$, Zhenwei $\mathrm{LI}^{2}$, Zhe Xie ${ }^{3}$, Luxin Zhao ${ }^{2}$, Chen ZHANG ${ }^{1}$, Xinyang HAN ${ }^{1}$ \\ ${ }^{1}$ State Grid Energy Research Institute, 102209, Beijing, China \\ ${ }^{2}$ State Grid Xiongan New Area Electric Power Supply Company, 071000, Xiongan, China \\ ${ }^{3}$ College of Information and Electrical Engineering, China Agricultural University, 100083, Beijing, China
}

\begin{abstract}
In recent years, the energy revolution has become a key in city development and leading economy. This article analyzes the current situation of energy development and city. Firstly, this article analyzes four aspects of problem of coordinated development. Then, this article has classified the city into two major systems. Finally, the correlation between energy and city is analyzed. Not only energy acts as a breakthrough in city development, but also the evolution of urban spatial form affects energy supply patterns.
\end{abstract}

\section{Introduction}

Cities are the core of economic development and the main energy consumer. The development of cities is inseparably supported by energy systems, while the development of energy systems also promotes the high-quality development of cities. In future urban developments, energy technology innovation will lead energy substitution and eventually trigger a new round of energy revolution[1]. The energy revolution acts as an important breakthrough to adapturban development and leadthe new normal of the economy, as well as being a key driving force for turning urban production and lifestyles into green-cycled, clean, and low-carbon, and a key thrust for enhancing comprehensive city competitiveness. It plays a giant role in promoting industrial transformation, deepening scientific and technological innovation, gathering high-end talents, promoting industrial innovation, and acts as an effective means for promoting new urbanization and new smart city construction[2].

From the perspective of a city, the energy system is a sub-system of the city which constitutes a part of the city's infrastructure to assist the economic, social, livelihood, and cultural development[3]. With the transformation and upgrading of city development and the in-depth advancement from the energy revolution, the innovation and transformation of a city's energy system can lead to the more comprehensive development of various elements of a city, and the energy system will transform from a guaranteed supply to be the driving force for development.It is helpful to identify the key elements of energy driven urban development from the bottom, and provide practical energy solutions to solve the bottleneck of urban development by clarifying the relationship between energy and urban development, the internal relationship between energy system and urban systems, the interface elements between energy system and urban development and the path of coordinated development between energy and city. Therefore, it is necessary to study the relationship between energy and urban development. The research framework of this article is shown in Figure 1.

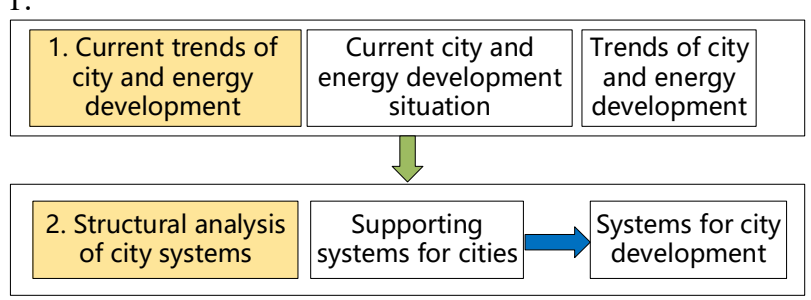

Figure 1 Idea map for Research on Energy-city Correlation

First, sort out the current situation of city and energy development. It dicusses and decides the evolution of driving factors in different stages of urban development from the development history of cities, and analyzes the problems and challenges of urban transformation. Then it expounds the current situation of urban energy development, analyzes the problems faced by urban energy, and studies and judges its future trend. Secondly,it deconstructs the urban system from the perspective of function, and explores the framework structure among the systems. This paper deconstructs the city from the two dimensions of support system and development system. Energy, information and transportation are used as infrastructure to support urban development. The interaction among the three systems is analyzed, and the transmission mechanism with urban economy, environment and space is studied. 


\section{Analysis of the Status Quo for the Development of Cities and Energy}

Population, resources, land area and other elements constitute the basic conditions for the survival of a city. With the increase of population, economic activities are becoming more and more frequent, people have higher and higher requirements for urban development, and the direction of regional development of human beings has gradually changed from agricultural society to industrial society[4]. In the process of industrialization, cities have brought about the growth of economic capacity, the improvement of residents' living standards and diversified social activities. The growth and expansion of each index represents the increase of corresponding energy demand. At this time, the large-scale development of industrial economy and the acceleration of urbanization gradually formed the regional economic center, accompanied by the high concentration of population, production and consumption materials. Due to the characteristics of urban regional development, the high concentration of materials has broken the overall balance of the city. The contradiction of urban development has become increasingly prominent. The first problem is the coordinated development of urban economy, energy and environment.

\subsection{Huge energy demands in cities}

Cities are the main contributors of world GDP and the main body of energy consumption. They have huge demand for energy, and $80 \%$ of energy consumption is concentrated in cities. At present, the energy demand of cities is huge, and with the expansion of city scale and the development of economy, the energy demand of some cities will increase steadily in the future.

Table 1 Estimated Energy Demand of Typical Cities Unit: TWh

\begin{tabular}{|c|c|c|}
\hline City & $\mathbf{2 0 3 0}$ & $\mathbf{2 0 5 0}$ \\
\hline New York region & 1300 & 1600 \\
\hline London region & 166 & 189 \\
\hline Beijing region & 750 & 900 \\
\hline Shanghai region & 1250 & 1600 \\
\hline Tianjin region & 950 & 1200 \\
\hline Sum of major cities in the world & 166000 & 190000 \\
\hline Global total & 210000 & 240000 \\
\hline
\end{tabular}

\subsection{Lack of Urban Energy Resources}

The primary energy in the city mainly includes renewable energy such as wind energy and solar energy. At present, the amount of renewable energy in the city is not high, and the total amount of renewable energy that can be exploited in the future is also very limited. There is a big gap in energy supply, and most of the energy needs to be imported from outside, which leads to serious resource shortage.

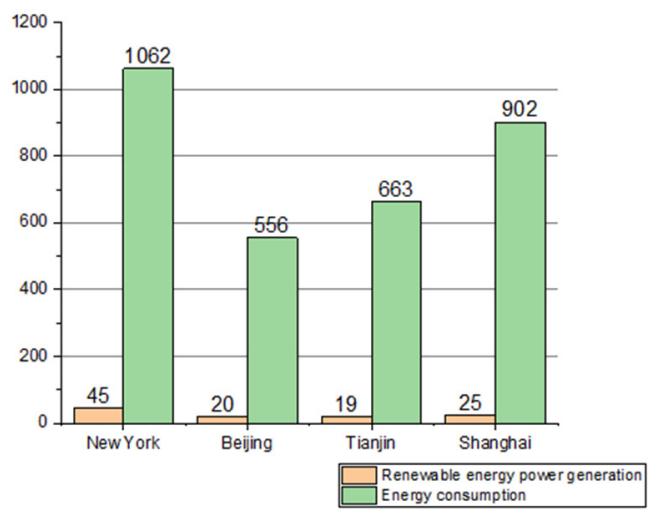

Figure 2 Renewable Energy Power Generation and Typical Energy Demands in Cities (TWh)

\subsection{Urban Energy Pollution is Serious}

Fossil fuels are still an important source of urban energy consumption. Greenhouse gases, harmful gases and dust particles produced in the process of production, transmission, transformation and consumption cause serious pollution to the urban atmosphere, soil and water resources. World Health Organization released the global urban air quality situation. As shown in Figure 2, air quality in $89 \%$ of cities does not meet health standards.

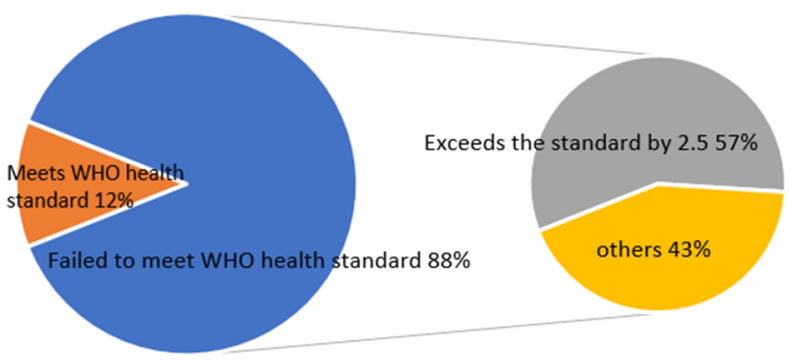

Figure 3 Global Urban Air Quality Report Released by WHO

\subsection{Insufficient Coordination of Urban Energy}

The traditional idea of urban energy development is to plan and design in disciplines, operate independently, and 
balance the power/gas/oil/cold/hot energy supply systems. Due to the lack of coordination and interconnection between the systems, the load peak to valley difference is large, and the equipment utilization rate is low, resulting in waste of investment, operation risk and increase of operation and maintenance cost.To sum up, urban energy development is faced with the problems of huge demand, lack of energy resources, serious energy pollution and insufficient energy coordination, which has increasingly become the bottleneck restricting economic and social development. We must look at the problem of energy development from the perspective of urban development demand, face the requirements of energy system in the process of urban industrialization and urbanization, and promote the transformation of energy from concept and path to promote the sustainable and healthy development of urban economy and society.

\section{Analysis of Energy-city Correlation}

\subsection{Decomposition of a City's Structure}

Based on the functional orientation of energy system in the future urban development, this paper divides the city into development and support systems. Among them, industrial development, population and labor force, public services and environmental protection are the main focus of sustainable development of urban economy, society and environment, which together constitute the urban development system; information system, transportation system and energy system, as the main aspects of urban infrastructure, work together with architecture to form the urban spatial form and provide support for urban development [5]. As the original capital of urban development, natural resources provide natural material support for various elements of the city. As the key link between urban physical infrastructure and economy, society and environment, energy system will lead infrastructure upgrading through energy revolution, thus making positive contribution to urban development.

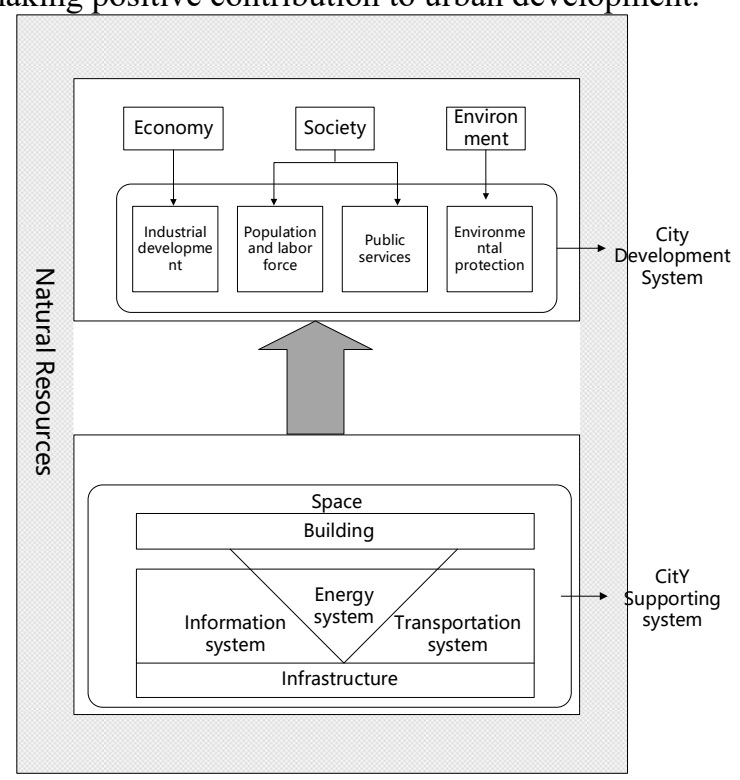

Figure 4 Urban system structure diagram

\subsection{Analysis of the Energy-city Correlation}

Considering city's development orientation, energy system as a link between urban products and the industrialization process is accelerating. The city's economic growth has been steadily improved, the city's population rate has increased significantly, and the industrial structure has been optimized and upgraded[6]. Industrial structure optimization and adjustment, economic growth, population rise and other urban development trends will directly affect the total demand and utilization mode of various energy varieties (coal, oil, natural gas, heat, electricity and other energy), and then affect the pattern of energy supply and demand. The production, allocation, conversion and consumption of energy all need to adapt to the needs of social and economic development. At the same time, due to the limited urban environmental capacity, it is particularly important to establish a low-carbon, clean, efficient and sustainable urban energy supply system in order to ensure the orderly development of urban economy and the healthy life of residents. Similarly, the promotion and development of urban energy system itself has a positive role in promoting urban economic development. Therefore, with energy reform as the core, this chapter analyzes the relationship between urban development and energy change from three dimensions of industrial development, ecological environment and spatial optimization, and analyzes the relationship between information, energy and transportation as the basic support and the impact on industry, ecology and space. 


\subsubsection{Correlation Between City Development and Energy Systems}

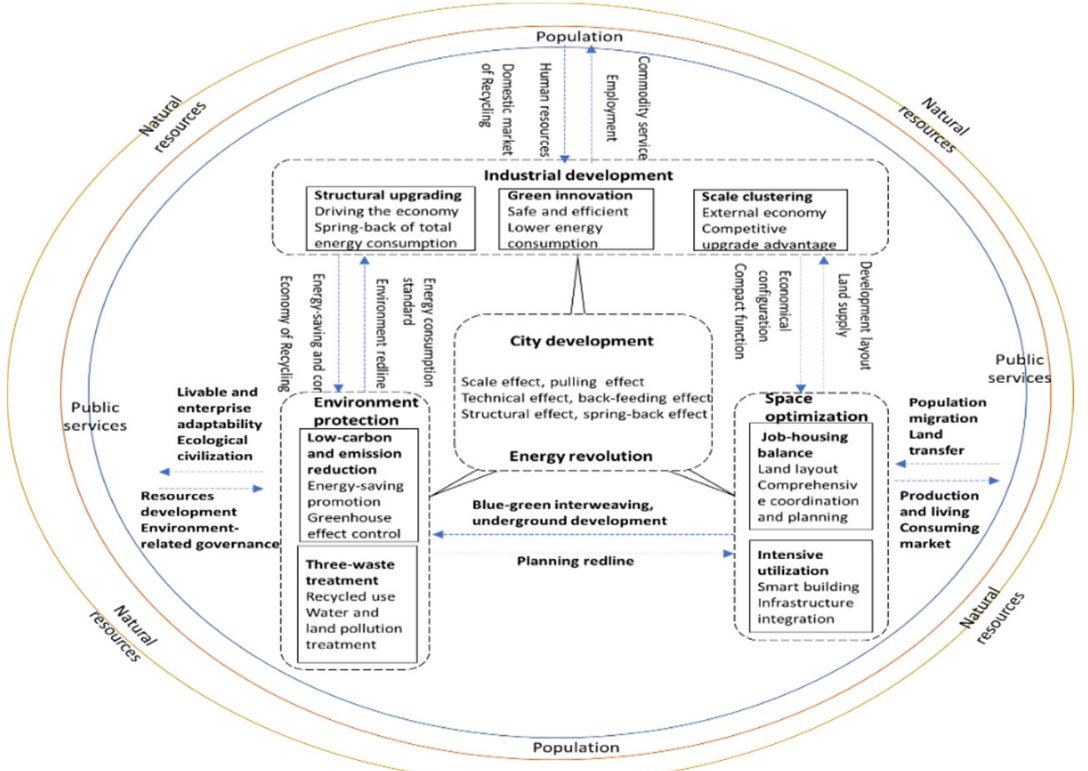

Figure 5 Correlation between Energy and City Development

As shown in the transmission mechanism among multiple systems in the figure, urban development is the result of the interaction among industrial development, environmental protection and spatial optimization. Industrial development meets the environmental protection requirements through circular economy, energy conservation and consumption reduction, and environmental protection contents such as low-carbon emission reduction and three wastes treatment will promote the industrial structure upgrading and green transformation; the balance of work and residence and intensive utilization are two important functions of spatial optimization, which will promote the development of industry towards scale agglomeration. At the same time, industrial agglomeration promotes the spatial allocation to be more economical and function to be tighten.In summary, the interactive correlation between city development and urban energy systems is specifically presented as follows:

(1) From the perspective of the correlation between urban economic development and energy, the sustainable growth trend of the urban economy calls for the continuous reduction of energy intensity to achieve energy-saving and efficient development of energy systems.

(2) From the perspective of the correlation between the urban environment and energy, the limited urban environmental capacity calls for a reduction of pollutants, emissions, and to achieve the development of a clean and environmentally friendly energy systems.

(3) From the perspective of the correlation between climate change and energy, the urban low-carbonization trend calls for the reduction of greenhouse gas emissions and achieving the development of a low-carbon energy system.

(4) From the perspective of the role of urban energy in promoting city development, the technological, innovation, and economic improvement of urban energy systems will provide more efficient and more economical energy for city development.

\subsubsection{Illustration of the Relationship Between Urban Support Systems}

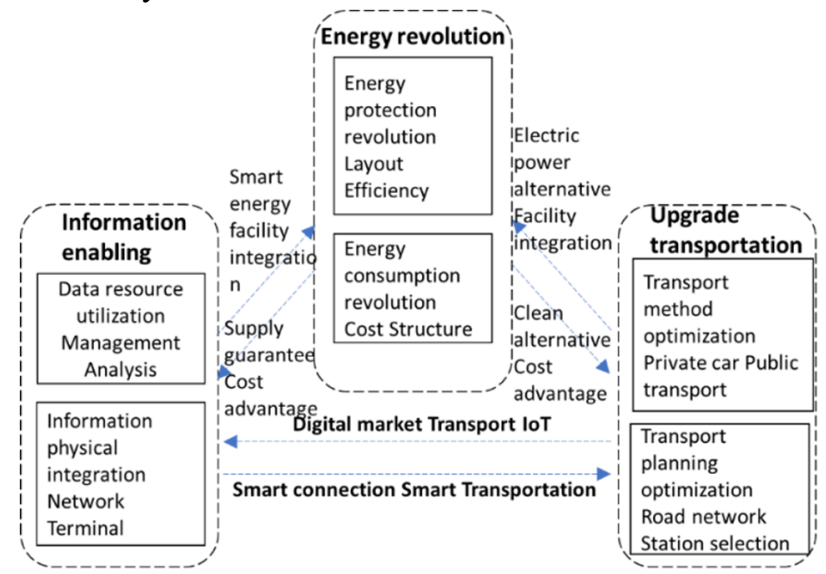

Figure 6 Correlation Between Urban Support Systems 
In the urban support system, transportation is an important link and is the main channel for transporting people and logistics for city development. As the main driving force of city development, transportation is an important factor for selecting a location for industrial use or adjusting the industrial layout. The information infrastructure is the prerequisite and foundation for the construction and application of various fields of informatization, representing new productivity and new development orientation, and leading industrial innovation and driving transformation. The energy revolution brings about not only changes in the production and consumption of energy itself, but also in-depth integration with information and transportation, and the two-way flow and sharing of information flow, traffic flow, and energy flow.

\subsubsection{Illustration of the Correlation Between Energy and Urban Industry}

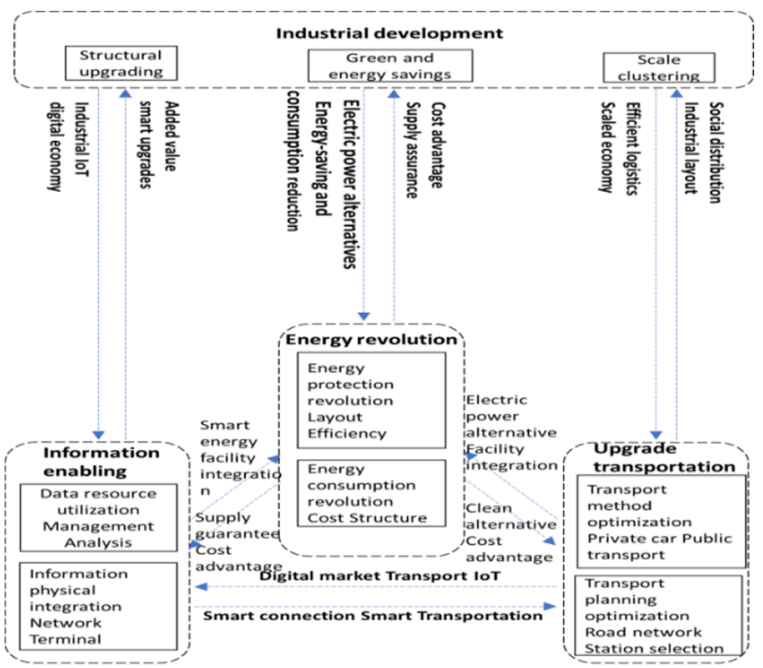

The energy production and consumption side revolution will promote the industrial evolution towards structural upgrading, green transformation and scale agglomeration. Economic growth will increase the demand for total energy, and new demand will also arise for the variety and structure of energy products. On the other hand, the new requirements of industrial development promote the energy revolution in depth. Industrial development promotes energy development and provides market demand, material security and technical support[7].

\subsubsection{Illustration of the Correlation Between Energy and Urban Environment}

Figure 7 Correlation Between Energy and Urban Industries

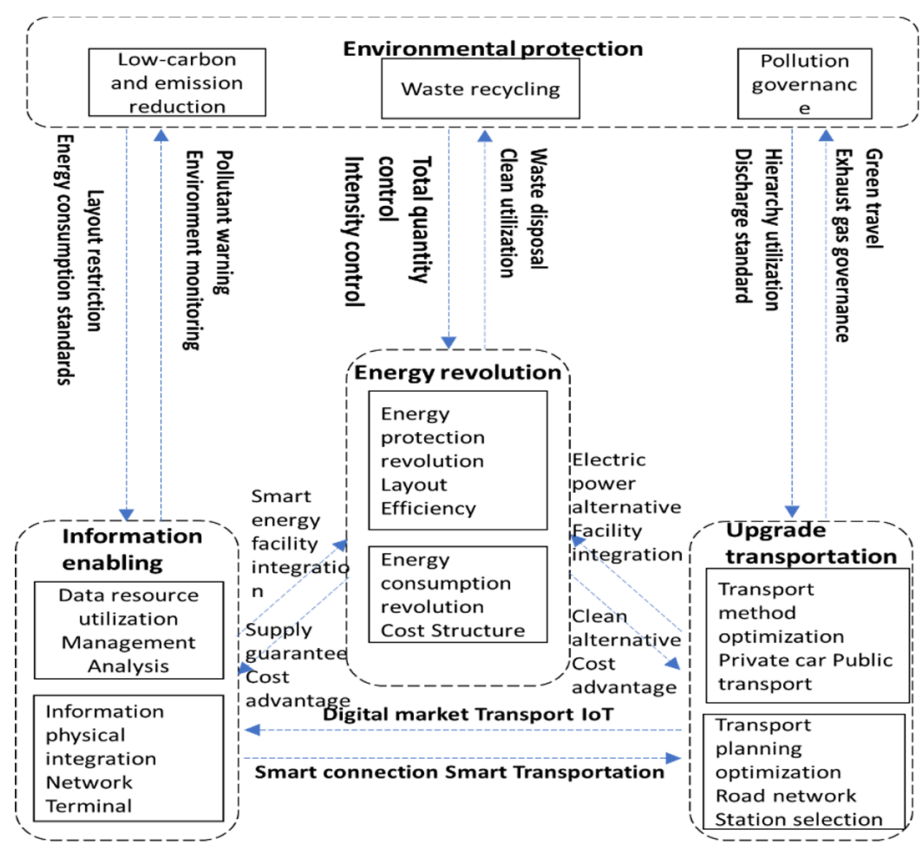

Figure 8 Correlation Between Energy and the Urban Environment 
Energy utilization comprises the main source of urban pollution. Unreasonable energy consumption is the main cause of urban air pollution. Traditional coal-burning pollution has not yet been solved, but the problem of motor vehicle pollution has become increasingly critical in some cities. On the other hand, the construction of ecofriendly civilization is forcing urban energy transformation. The proposal of eco-friendly construction calls for the transformation of urban energy production and consumption, energy conservation, the clean use of fossil fuels, and the development of non-fossil fuel energy are the three pillars of the future city's green and lowcarbon energy strategy.

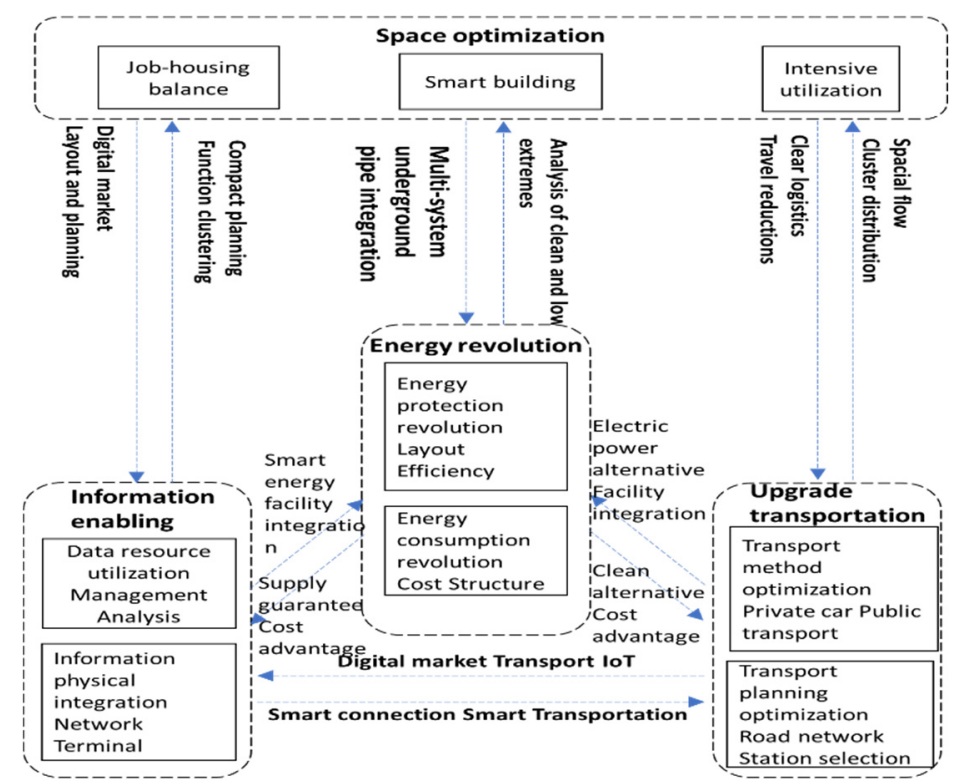

Figure 9 Correlation Between Energy and Urban Space

\subsubsection{Illustration of the Correlation Between Energy and Urban Space}

The evolution of urban spatial form shapes different urban energy consumption structures, thereby affecting urban energy supply patterns. For example, the energy consumption structure for production, transportation, and building operations in multi-center, high-density cities has been optimized to some extent. On the other hand, the energy system restricts the development of urban spaces. In the past quite a long time in order to meet the large amount of energy needed by the urbanization process, based on the traditional energy supply idea of "expansion and supply guarantee", a number of super large and centralized energy centers have been standing around the city, providing power for the development of the city.

\section{Conclusion}

Due to the high concentration of materials caused by the regional development characteristics of cities, the coordinated development of urban economy, energy and environment is becoming increasingly prominent. The problem of coordinated development mainly embodies the following four aspects: Huge energy demands in cities, Lack of Urban Energy Resources, Urban Energy Pollution is Serious, Insufficient Coordination of Urban Energy.

Therein, industrial development, population, labor, public services, and environmental protection are the main focus points for sustainable development of urban economy, society, and environment, which, together, constitute the system by which a city develops. The information system, transportation system, energy system and buildings to form a spatial city and support city development.

Finally, the relationship between energy and city is analyzed. A city's development is the result of the interaction of industrial development, environmental protection, and space optimization. The energy revolution brings about not only changes in the production and consumption of energy itself, but also in-depth integration with information and transportation, and the two-way flow and sharing of information, traffic, and energy that flow between them. Energy utilization comprises the main source of urban pollution. The evolution of urban spatial form shapes different urban energy consumption structures, thereby affecting urban energy supply patterns.

This work is supported by Management Consulting Project of SGCC (Research on Enterprise Development Management Mechanism and Operation Mode Based on the Energy Internet Planning and Construction of State Grid Xiong'an New Area Electric Power Supply Company)

\section{References}

1. Zhang Ming, Ding Chengri, Cervero R. Integration of Land Use and Transportation: New Urbanism and Rational Growth[J]. City development Research, 2005,12(4):46-52.

2. Long Weiding, Bai Wei, Liang Hao, et. al. Urban Form and Energy Vision of Low-Carbon 
Cities[J].Building Science,2010,26(2):16-21 26.

3. Jia Hongjie, Mu Yunfei, Yu Xiaodan. Thinking on the Development of China's Integrated Energy System[J]. Electric Power Construction, 2015,36(1):16-25.

4. Tu Zhengge, Ye Hang, Chen Renjun. Dynamic Mechanism and Development Model of China's Urbanization[J]. Journal of Central China Normal University (Humanities and Social Sciences Edition),2016,55(5):45-54.

5. Fang Weiwei. Information Technology and Optimization of Urban Spatial Structure[J]. City development Research, 2006(1):30-33.

6. Zhao Xiaogang, Xue Jiliang. Research on the Dynamic Correlation between Energy Consumption and Economic Growth Based on the Kuznets Curve Model[J].Statistics and Decision,2011(11):130-131.

7. Han Zhiyong, Wei Yiming, Jiao Jianling, et. al. Cointegration and Causality Analysis of China's Energy Consumption and Economic Growth[J]. System Engineering, 2004,22(12):17-21. 